\title{
Food biotechnology and education
}

\author{
Daniel Ramón* \\ Instituto de Agroquímica y Tecnología de Alimentos \\ Consejo Superior de Investigaciones Científicas \\ Apartado Postal 73, 46100-Burjassot \\ Valencia, España \\ Tel: 34963900022 \\ E-mail: daniel.ramon@iata.csic.es \\ Alicia Diamante \\ Fundación REDBIO Internacional-B \\ Montevideo 666, Piso 10 Of. 1007, CP 1019 \\ Capital Federal, Buenos Aires, Argentina \\ Tel: 5491143714065 \\ E-mail: adiamante@redbio.org \\ María Dolores Calvo \\ Instituto de Formación Profesional Superior Número 2 \\ Complejo Educativo de Cheste \\ Conselleria d'Educació de la Generalitat Valenciana \\ Cra. Madrid s/n, 46380-Cheste \\ Valencia, España \\ Tel: 34962525542 \\ E-mail: mcalvo321b@cv.gva.es
}

Financial support: Our work is supported by the project BIOEDUCAR of CYTED.

Keywords: food biotechnology, genetically modified foods, public perception, young consumers.

Abbreviations: GM: genetically modified

GMO: genetically modified organism

It is clear that the future of our children will be marked by the development of two scientific disciplines: computing and biotechnology. Regarding the first, during recent years considerable progress have been done in many countries around the globe aimed at enhancing the teaching in these subjects and, at the same time, encouraging the use of computers in classrooms. On the contrary, training in biotechnology is absent in many secondary schools of the planet. This formative deficiency generates citizens whose opinion on the marketing of biotechnological products is easily manipulated by both defenders and opposers of biotechnology. This situation is of particular relevance when the item in question is food biotechnological applications that provoke an intense social debate and more specifically the so-called genetically modified foods (GM foods). In this article we report a survey carried out with $\mathbf{5 0 0}$ young Spanish consumers in order to discover their attitudes to GM foods. The work has been focused on the study of the perception of GM foods and their labelling. The results indicate that they are moderately receptive to GM foods but like to be informed through labelling. However, the most important conclusion of the survey is the lack of sufficient knowledge about food biotechnology and genetic engineering on the part of young Spaniards. It is therefore very important that an unbiased presentation of the scientific basis of biotechnology should be introduced in secondary education. In this sense, the project BIOEDUCAR is an important tool to introduce unbiased information about food biotechnology in the Latin America and Spanish secondary schools.

For thousands of years man has been applying genetics to achieve the improvement of raw materials and final food products. Using selective breeding and/or mutagenesis, a large number of plant varieties, animal races and microbial starters have been produced. In fact, food biotechnology is the oldest biotechnology. Recently, recombinant DNA techniques have been applied in food technology creating the so-called 'genetically modified foods' (GM foods), a class of novel foods (Halford and Shewry, 2000). Transgenic potatoes useful as an oral vaccine against cholera (Arakawa et al. 1998), recombinant wine yeasts able to produce wine of increased fruity aroma (Manzanares et al. 2003) and transgenic cows or ewes

*Corresponding author 
producing milk with high levels of pharmaceutical proteins (Sabikhi, 2007) are some of the results of the new food biotechnology. This new technology differs in three respects to previous techniques: i) directed change $v s$ the random nature of breeding, ii) greater efficacy (less time to obtain the desired change), and iii) the possibility of crossing the species barrier and thereby generating transgenic organisms. The latter has important ethical and social repercussions.

After years of research, the first GM food, a transgenic tomato that softens more slowly, appeared in US supermarkets in 1994. Since then, other GM foods have obtained permission for commercialisation in the US and a general atmosphere of public acceptance of GM foods is perceived (Harlander, 2002). In Europe the situation is quite different (Moseley, 2002; Einsele, 2007). In mid 1997, the European Union (EU) established the "Novel Food Regulation", a legislative system for pre-market evaluation and approval for the commercialisation of GM foods. Previously, certain European countries such as the United Kingdom and The Netherlands developed their own legislations which were subsequently abolished after the official acceptance of the aforementioned European regulation (Calvo et al. 1998). Most recently, some specific regulations dealing with research and release of genetically modified organisms (GMOs) into the environment, intellectual property, commercialization, labelling or, inclusively, unintentional movements of GMOs between member states have been approved (Ramón et al. 1998; Ramón et al. 2004). As a result, GM foods are now appearing in European supermarkets.

It is evident that public reaction is a crucial factor for the progress of the novel food biotechnology (Ramón, 2000; Varzakas et al. 2007). What is the consumer opinion of GM foods? Since 1984, more than 70,000 people, mainly in the US, have been asked what they think about biotechnology (Zechendorf, 1994). Analysis of the responses demonstrated difficulties in making general statements due to dissimilarities between countries (e.g. cultures) and differences in consumer attitude depending on the kind of biotechnology being evaluated (e.g. pharmaceutical biotechnology vs food biotechnology). Consequently there is a need for national surveys about novel food biotechnology. In this article we present a study carried out with 500 young Spanish consumers in order to discover their attitudes to GM foods.

\section{The Spanish survey}

The current study involved two different surveys conducted before and after a short seminar about food biotechnology. A total of 514 young people, aged between 15 and 25 years, were interviewed and only 14 were eliminated due to erroneous completion of the survey. The average age of the respondents was 17.4 years and $40 \%$ were male. The seminar (20 min long) was dictated by a scientist actively working in food biotechnology. It was divided into three parts. The first was focused on the historical perspective of food biotechnology, the definition of GM foods and comments about differences between foods obtained by classical means or by novel food biotechnology. In the second part, different examples of GM foods were shown, discussing their origin (plant, animal or fermented foods) and also their beneficiaries (the producer, the consumer or both). In the third part, the EU Regulation dealing with GM foods was commented on with special emphasis on the sequential steps required to obtain permission for commercialisation (including safety assessment assays) and labelling of GM foods.

The first survey (10 questions) was conducted immediately before the seminar. Five of the questions were designed in order to discover the extent of background knowledge about biotechnology and food biotechnology. Two questions were intended to evaluate specific knowledge about GM foods and two others to check the attitude about legislation and labelling. The remaining question asked for a score to be assigned to different institutions regarding their credibility in the evaluation of food health and environmental protection. The second survey (15 questions) was conducted after the seminar. Five of the questions were repeated from the first survey (four concerning general knowledge about biotechnology and food biotechnology and the fifth being the question regarding scores of credibility). Two questions were about risks associated with the consumption of GM foods and another seven about GMF labelling and legislation. The remaining two questions asked for preferences regarding consumption of different GM foods. A copy of the surveys is available upon request to the corresponding author.

\section{Young Spanish consumers' knowledge of food biotechnology}

Young Spanish consumers have a confused idea about biotechnology. For example, $48 \%$ of respondents chose as the most adequate definition of biotechnology "the use of living organisms for industrial purposes" in contrast to other definitions such as "to manipulate nature" $(36 \%)$ or "to mutate living organisms" (13\%). Only $12 \%$ agreed with the statement that "biotechnology and genetic engineering are the same" suggesting that the majority understand that biotechnology is a scientific discipline and genetic engineering is a technique. However, analysis of the answers to other questions indicates a different situation. Significant percentages of the respondents were of the opinion that biotechnology is a new (71\%) and artificial (51\%) scientific discipline. These apparent contradictions indicate a lack of knowledge about the nature of biotechnology. The situation concerning food biotechnology and GM foods is very similar. When asked "Would you eat a dairy product produced by microorganisms?", only 39\% gave a positive answer, indicating that around two out of three young Spanish consumers do not know that yoghurt is a biotechnological product. This is a similar percentage to that obtained in surveys in The 
Netherlands (Hamstra, 1993). When asked "Do you know what a GM food is?" $60 \%$ of respondents gave a negative answer.

We can conclude from these data that in Spain, as in other European countries (Hamstra, 1993; Lock, 1994), young peoples' knowledge of biotechnology is minimal. After the seminar some opinions changed. For example, only $37 \%$ of respondents considered biotechnology to be a new discipline and less than one quarter correlated biotechnology with the manipulation of nature. In addition, the level of uncertainty in the answers (i.e. "I am not sure") was reduced. This is a situation previously reported in similar inquiries (Lock, 1994).

\section{Young Spanish consumer perception of GM foods}

As in other countries, the majority of the respondents were very positive about GM foods. There was general approval (70-75\%) of the commercialisation of genetically modified crops or fermented foods. This approval seems to be related to the final beneficiary of the product: more than half of the respondents $(58 \%)$ were negative about the use of recombinant brewing yeasts that eliminate the industrial problem of filtration but were positive $(68 \%)$ about the use of recombinant yeasts producing wine with increased fruity aroma. The perception of health risks associated with the consumption of GM foods was also evaluated. Only $17 \%$ of the respondents thought that GM foods were less safe than conventional foods. However, it is our opinion that this general acceptance was correlated with the presentation during the seminar of the safety assessment studies carried out on GM foods. Our data support the previous findings that in Mediterranean Europe risk perceptions are lower and acceptance of GM foods is higher than in other countries. With respect to information about food health risks, young Spanish consumers expressed confidence in evaluations by the official institutions (Table 1). After the seminar, the opinions of consumers' associations, ecological groups and industrial companies were judged to be very similar. Relatively low confidence in the opinions of the communication media was apparent. In general, confidence scores increased after the seminar, most notably in the cases of consumers' associations and industrial companies (Table 1).

\section{Labelling of GM foods}

Labelling is probably the most important area of public debate concerning GM foods (Todt and Luján, 1997). An analysis of this issue has been previously carried out in Spain with representatives from the government administration body, several non-governmental organisations, trade unions, agricultural organisations, industrial companies and the scientific community (Todt and Luján, 1997). In this study, all the critics of genetic engineering were in favour of labelling. The opinions against labelling or asking for only limited labelling came from members of the scientific community and industrial companies. Our results indicate that young Spanish consumers are strongly in favour of labelling $(87 \%$ before the seminar, $91 \%$ after the seminar). Almost all are of the opinion to label all GM foods (independent of the specific nature of individual GM foods); however they do not consider it to be a good idea to label conventional foods as "free of genetically modified organisms" (only 6\% in favour). With respect to the kind of message on the label, nearly half chose a moderate option ("genetic engineering techniques have been employed in the production of this food"). In addition, a high percentage of respondents (around $90 \%$ before and after the seminar) were in favour of the existence of specific legislation for the commercialisation of GM foods.

In conclusion, young Spanish consumers are moderately receptive to GM foods but like to be informed through labelling.

During the last few months, Spanish newspapers have published news about GM foods. In most cases the articles contained negative views of food biotechnology and included many scientific errors. In this regard, the lack of sufficient knowledge about food biotechnology and genetic engineering on the part of young Spaniards may easily result in misinformed opinions. It is therefore very important that an unbiased presentation of the scientific basis of biotechnology should be introduced in secondary education, thus enabling all relevant issues to be adequately evaluated by the consumer and minimising the biased influence of interested parties (e.g. ecological organisations, industrial manufacturers).

\section{The BIOEDUCAR project}

The existence of deficiencies in biotechnology in existing secondary school educational programs provoked a mobilization in a group of educators and scientists from several Latin America countries. As a result, a proposal prepared by experts in education and science was presented to the CYTED program by the REDBIO International Foundation. The proposal, entitled BIOEDUCAR (bioteaching), was approved in 2006 and running from January 2007. The project is carried through by a general coordinator together with a group of experts per country.

The aim of this proposal is to coordinate all the available tools, strengths and opportunities for education in food biotechnology available in nine Latin American countries (Argentina, Bolivia, Brazil, Chile, Cuba, Ecuador, Mexico and Venezuela). The final objective is to encourage and facilitate communication between scientists and society in the fields of food biotechnology with a view to developjoint projects to implement various bodies of work, discussion or analysis.

BIOEDUCAR has created a permanent forum for discussion that includes scientists with expertise in food biotechnology and in impact analysis methodologies, as 
Table 1. Young Spanish consumers scores of confidence (average) in the opinions of food safety given by different institutions. Scores are from 1 to 7 indicating less to more credibility, respectively.

\begin{tabular}{|c|c|c|}
\hline Institution & Before the seminar & After the seminar \\
\hline Universities & 5.028 & 5.654 \\
\hline Industrial companies & 2.206 & 4.362 \\
\hline Ecological organisations & 4.364 & 4.448 \\
\hline Consumer associations & 3.724 & 4.604 \\
\hline Communication media & 2.208 & 3.144 \\
\hline Local health authorities & 5.506 & 5.791 \\
\hline Ministry of Health & 5.934 & 6.204 \\
\hline World Health Organisation & 6.498 & 6.748 \\
\hline
\end{tabular}

well as politicians and social actors. Also a working group for conducting courses and dictation of conferences has been created. Finally, various strategies for disseminating and/or training food biotechnology at the educational community (primary, secondary school and university students and the general public) have been developed. BIOEDUCAR maintains a website for public dissemination and education in biotechnology within the portal REDBIO/FAO through a site specifically for the Thematic Network BioEDUCAR.

\section{CONCLUDING REMARKS}

The development of tools for teaching biotechnology in the primary and secondary schools is a key target for the future. It is very important that an unbiased presentation of the scientific basis of biotechnology should be introduced to the students. The project BIOEDUCAR is an important tool to achieve these goals in Latin America countries.

\section{ACKNOWLEDGMENTS}

We express our gratitude to the teachers and students of the "Instituto de Secundaria de Caudete de las Fuentes", the "Instituto de Formación Profesional de Chiva" and the "Instituto de Secundaria Enric Valor de Silla" for their help and support during the surveys.

\section{REFERENCES}

ARAKAWA, T.; CHONG, D.K.X. and LANGRIDGE, W.H.R. Efficacy of a food plant-based oral cholera toxin B subunit vaccine. Nature Biotechnology, March 1998, vol. 16, no. 3, p. 292-297.
CALVO, M.D., PERIS, J. and RAMÓN, D. Some aspects about food, genes and legislation. Food Science and Technology International, 1998, vol. 4, no. 1, p. 1-4.

EINSELE, D. The gap between science and perception: the case of plant biotechnology in Europe. Advances in Biochemical Engineering and Biotechnology, 2007, vol. 107, p. 1-11.

HALFORD, N.G. and SHEWRY, P.R. Genetically modified crops: methodology, benefits, regulation and public concerns. British Medical Bulletin, January 2000, vol. 56, no. 1, p. 62-73.

HAMSTRA, A. Consumer acceptation of biotechnology: look at both consumers and products. IFI, 1993, vol. 4, p. 4-9.

HARLANDER, S.K. Safety assessment and public concern for genetically modified food products: the American view. Toxicologic Pathology, 2002, vol. 30, no. 1, p. 132-134.

LOCK, R. What do 14 to 16 -year-olds know and think about biotechnology? Nutrition and Food Science, 1994, vol. 94 , no. 3, p. 29-32.

MANZANARES, P.; OREJAS, M.; GIL, J.V.; DE GRAAFF, L.H.; VISSER, J. and RAMÓN, D. Construction of a genetically modified wine yeast strains expressing the Aspergillus aculeatus rhaA gene, encoding an $\alpha$-Lrhamnosidase of enological interest. Applied Environmental Microbiology, December 2003, vol. 69, no. 12, p. 75587562 . 
MOSELEY, B.E.B. Safety assessment and public concern for genetically modified food products: the European view. Toxicologic Pathology, January 2002, vol. 30, no. 1, p. 129131.

RAMÓN, D. Genetically modified foods: a case of information or misinformation. International Microbiology, March 2000, vol. 3, no. 1, p. 1-2.

RAMÓN, D.; CALVO, M.D. and PERIS, J. New regulation for labelling of genetically modified foods: a solution or a problem? Nature Biotechnology, 1998, vol. 16, no. 10, p. 889.

RAMÓN, D.; MACCABE, A.P. and GIL, J.V. Questions linger over European GM food regulations. Nature Biotechnology, February 2004, vol. 22, no. 2, p. 149-150.

SABIKHI, L. Designer milk. Advances in Food and Nutrition Research, 2007, vol. 53, p. 161-198.

TODT, Oliver and LUJAN, Juan Luis. Labelling of novel foods and public debate. Science and Public Policy, October 1997, vol. 24, no. 5, p. 319-326.

VARZAKAS, T.H.; ARVANITOYANNIS, I.S. and BALTAS, H. The politics and science behind GMO acceptance. Critical Reviews in Food Science and Nutrition, May 2007, vol. 47, no. 4, p. 335-361.

ZECHENDORF, B. What the public thinks about biotechnology. Nature Biotechnology, vol. 12, no. 9, p. 870-871. 